\title{
Hypotheses on Agony: Field Research in a Genocidal Context
}

Sarah Kenyon Lischer, Wake Forest University

ABSTRACT Drawing on my field research experiences in Rwanda, Bosnia, and Cambodia, I present a personal narrative that creates a vivid picture of field research in challenging environments and contemplates what research ethics look like in post-genocide societies. Working in violent, traumatized, or oppressive conditions reveals the fragility of traditional political science methods when confronted with the realities of human suffering. Part of the intrinsic value of field interviews is the unique interactive experience between researcher and respondents, which can never be fully replicated. Addressing the controversies about research methods, I argue that the Data Access and Research Transparency (DA-RT) versions of protection, replicability, and transparency undermine the integrity of field research and can threaten the security of researchers and respondents. This article also reflects on the personal experience of working in three post-genocide societies, including the effects of trauma and empathy. Despite the difficult subject matter and personal challenges, I continue to champion field research for the unmatched understanding it offers researchers. This reflection encourages a broader discussion about the value of human interaction in the research process, even if those interactions do not fit neatly into a methodological template.

One of the most difficult narratives to hear is the telling of a trauma. It takes its toll on the listeners and is not always therapeutic for the narrator.

-Susan Brison, Aftermath: Violence and the Remaking of a Self

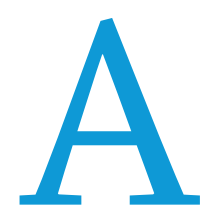

$\mathrm{t}$ close range, the bones in a human skull create a patchwork of seams reminiscent of the stitching in my grandmother's quilts. As if in a trance, I observe that the thousands of skulls piled behind cracked glass all exhibit a similar delicate tracery. The bones, although inanimate, lie naked and vulnerable and silent. Focusing on a particularly small skull, I remember the birth of my first child, and my alarm at the terrifying fragility of the pulsating softness at the crown of his head. As an anxious new mother, how I guarded that tender area, protected only by a haze of down. I imagine many new mothers share the relief that I felt when the infant cranial bones finally fuse in one of the body's first acts of self-protection.

Sarah Kenyon Lischer (iD) is associate professor of politics and international affairs at Wake Forest University. She can be reached at lischesk@wfu.edu.
A leafy tree flourishes near the glass tower filled with human remains. A sign informs visitors that, to save bullets, the Khmer Rouge soldiers bashed babies' heads against this tree. Despite the baking heat, I avoid the contaminated shade. The sounds I hear filtering through the surrounding vegetation must be from a nearby school: children at recess. Chickens roam aimlessly in the scrubby grass. A stray dog crosses my path and I continue past the executioners' tree. Another sign requests in English and Khmer: "Please do not walk on the mass graves." Amid the dry bones at the Choeung Ek genocide memorial (colloquially termed "the killing fields"), I am enveloped in the tangible horror of 40 years earlier. ${ }^{1}$ Suddenly, "data collection" seems far less sterile than it did in my grant applications.

Here, social science crumbles like the dust of the decomposing dead. Transfixed by piles of skulls, my field research feels irrelevant and irreverent. Why did I assume that watertight hypotheses would arm me to confront unbearable agony? Contemplating this suffering, I see the weaknesses in my rigorous scholarly approach, the elusive truth suffocating beneath layers of literature review and methodology. I do not have recourse to a neutral, disinterested space from which to observe the anguish of strangers. I planned to 
conduct Institutional Review Board (IRB)-approved semistructured interviews with a carefully selected sample of respondents; instead, I find myself invited into the personal hell of genocide survivors. Likewise, my own suffering, traumas, and griefs begin to escape the confines I have created for them. Experiencing the shattered remnants of a traumatized societyeven as an outsider-breaks through my supposed barrier of scholarly disinterest, revealing the impossibility of segregating emotions from intellect. Standing near that cursed tree in Cambodia, I want answers, not hypotheses. Why did this particular sickening atrocity happen? A particular teenager, a particular infant. How can my academic training help me understand such cruelty? In Cambodia, I reluctantly accept that all the hypotheses in the world cannot adequately explain a teenaged Khmer Rouge soldier bashing a baby's head against a tree. methodological flexibility in political science research. Although I focus on a genocidal context, this analysis likely applies to research in other challenging contexts, such as displaced and impoverished populations.

\section{SOCIAL SCIENCE IN THE "KILLING FIELDS"}

The memory of trauma has festered in Cambodia for decades, becoming part of the fabric of the country's existence. Under the leadership of Pol Pot, the Khmer Rouge regime ruled from 1975 to 1979. During that time, almost two million Cambodians died, many from hunger. The country became a vast slave-labor camp: the rulers banned religion, money, and education. They controlled all food intake. A person caught gleaning a nut from the forest faced certain execution. The Khmer Rouge taunted the doomed with its proverb: "To spare you is no profit, to destroy you is no

\section{In Cambodia, I reluctantly accept that all the hypotheses in the world cannot adequately explain a teenaged Khmer Rouge soldier bashing a baby's head against a tree.}

Scholars use the term "field research" when we travel to distant places to investigate our chosen topic through observing, participating, interviewing, and interpreting. We label genocide survivors as "subjects," mass graves as "research sites," and traumatized communities as "the field." Graduate school generally trains the budding researcher to ignore emotional responses to the data; her analytical mind should not be clouded by shock or grief or empathy or outrage. The scholar should focus patiently on the prize-a convincing hypothesis backed up by solid evidence. That is my plan when I arrive in Phnom Penh with my well-vetted research questions and hypotheses, multiple funding streams, and experience working in challenging political environments.

Cambodia is not my first encounter with dry bones. Only four months prior, I made my first trip to Bosnia and Herzegovina and immersed myself in the memory of the Srebrenica genocide, where Bosnian Serbs brutally killed 8,ooo boys and men in 1995. Before that, I conducted interviews in Rwanda, listening to survivors' personal narratives, and visited the corpse-filled memorials to that atrocity. By the time I leave Cambodia, I will feel weighed down with the suffering of the people I have connected with on my journey. I also will realize that traditional methodological templates are insufficient for researching in a genocidal context.

This article uses the narrative framework of my own experiences to contribute to the ongoing discussion about the standardization of research methods in political science (DA-RT 2012; Elman and Lupia 2016; Fujii 2016; Tripp 2018). I find that field research among people traumatized by genocide and human rights atrocities differs from other types of research, requiring an approach that considers trauma, suffering, insecurity, and empathy. After Cambodia, Bosnia, and Rwanda, I determine that research ethics benefit from a human-centric approach that prioritizes the protection of subjects in potentially harmful environments rather than strict adherence to generic protocols. Scholarly disinterest may not be possible (or desirable) in fieldwork among these populations. Researchers instead may find that emotion and personal history affect their interactions more than expected. These departures from disciplinary norms do not invalidate work done in a genocidal context; rather, they highlight the need for loss." In a lush, fertile land, people starved with unattainable food in plain view. Scores of memorials throughout the country commemorate those deaths. Most genocide memorials are part of a larger temple complex, called a "wat." The wat may include a temple, a monastery, numerous smaller shrines, and stupas (i.e., traditional bell-shaped towers erected as Buddhist shrines) to house the bones and relics of the dead. Even now, decades after the genocide, the political manipulation of memory impedes the potentially healing effects of memorials (Lischer 2019).

I have come to Cambodia to observe and conduct interviews at genocide memorials as part of a project on the politics of public memory. My interpreter Hourn and my driver Mr. Kevin help plan our trips to various memorials in the countryside, starting with Wat Champuh Ka-Ek in Kandal province. Arriving at the large and flashy temple complex, Hourn explains that the prime minister Hun Sen (Asia's longest ruling dictator) has been spending lavishly on religious structures such as this one, mostly for political purposes. While at this memorial, I hope to engage some of the monks in conversation, as well as the lay attendants who help maintain the wat. In Cambodian Buddhism, monks play an integral role in shepherding the dead to the next cycle of rebirth. As Mr. Kevin parks the car in a cloud of dust, the only people I see are a group of small boys. Nearby is a concrete stupa, a glasswalled cube surrounded by four columns and a lotus pond. The unprepossessing glass box contains bones, mostly skulls. The boys jostle one another and chatter in Khmer, laughing-most likely at the strange foreigner peering through cracked glass at cracked skulls. The only sign of the monks is their laundry: saffron robes flapping in the breeze on a distant clothesline. ${ }^{2}$

The temple complex surrounds a large rectangular manmade pond with concrete borders; moving shadows suggest that the pond is stocked with fish. As I approach the edge to peer at them, a local man proudly tells us that the catfish can weigh as much as 3okg. I continue walking, past where the monks live and toward a cart where a woman sells drinks and snacks. She seems eager to tell us the story of her surroundings: the Khmer Rouge arrived when she was a girl and "evacuated" her from her home. After the fall of the Khmer Rouge, she returned and discovered thousands of 
bodies and bones. She points to an area about 100 meters away, where the monks gathered the bones and conducted a proper Buddhist ceremony, with the remains preserved in the stupa, cremated, or buried. Hun Sen's new pagoda now squats on the burial site. The vendor speaks with animation and clear disdain for the current government.

As we talk, the woman conducts business with the small boys, who exchange a few grubby coins for a clear plastic bag filled with what looks like water but is pressed sugarcane. Mr. Kevin buys two bags of dried noodles and everyone pauses to watch the fish leap up, their mouths gulping wide to swallow the treats. The woman says that her livelihood depends on people coming to see the fish. After she tells me that only Cambodians will eat the pressed sugarcane (which I take as a direct challenge), she feeds the stalks into a noisy machine so I can try it. In a hospitable gesture, Hourn pays the few cents for both of our bags and I, like the boys, slurp down the deliciously sweet drink.

In that moment, I do not care about my grant proposal to investigate "how interactions between Western interpretations of the narrative and the domestic discourse in the post-atrocity country affect the evolution of public memory." I care about the entrepreneurial sugarcane vendor who remembers the slaughter that saturates the very soil we stand on. I care about the rascally little boys, born decades after the genocide yet still surrounded by its detritus. I care about Mr. Kevin who finds joy in his young son even though he can never forget his family's trauma. The land holds unknown thousands of dead bodies, just as so many Cambodians hold their own secrets and memories. My hypotheses shrivel in the face of such agony.

\section{METHODOLOGICAL CHALLENGES IN GENOCIDAL CONTEXTS}

"Conducting research on violence, pain, and trauma is challenging for the researcher, the informants, and the readership" warns a veteran field researcher (Ross 2009, 183). In addition to those challenges, field research has been caught up in ongoing methodological debates about transparency, ethics, and replicability in political science. In 2012, an ad hoc group of scholars developed the principles of DA-RT that then were added to the American Political Science Association ethics guide. The DA-RT (2012) principles state that researchers have "an ethical obligation to facilitate the evaluation of their evidenced-based knowledge claims through data access, production transparency, and analytic transparency so that their work can be tested or replicated." The DA-RT versions of protection, replicability, and transparency undermine the integrity of field research and can threaten the security of researchers and respondents. cases, publicizing the identity of interviewees and the information they share has resulted in physical harm, interrogation, or imprisonment. Regarding photographs of lynchings that Fujii (2016) analyzed in her work, she argues that publicizing such abhorrent images as "data" is not an objective act and can have negative political consequences, even though the subjects of the photographs can no longer object. Tripp $(2016,728)$ comments that "part of the problem is that grounding such requirements [for public release of research materials] in a positivist view of science makes it especially difficult to see that there are multiple ways of being transparent."

Field researchers need context-specific protocols for protecting people and data during research. Experienced field researcher Mertus $(2009,173)$ reminds scholars working in authoritarian states to store their information off of their laptop and out of the country-and even to "use a code when identifying local sources in research notes." As part of my preparation for the Rwanda trip, I contacted researchers with extensive experience in the region and read accounts of the restrictive political environment. One scholar had her passport confiscated and was dumped in a "reeducation" camp; another recounted that her research assistant was detained and interrogated after her departure; and a researcher still in Rwanda declined to communicate via email and spoke only briefly on the phone, whispering how I must protect respondents and keep my data from the government. ${ }^{3}$ In situations in which the ethical imperative to do no harm conflicts with the methodological demand for transparency, practiced field researchers likely will sacrifice the latter.

Replicability of a research process generally is viewed as evidence of rigorous scholarship in the natural and social sciences. The narrative characteristics of ethnographic and interview-based research suggest the impossibility of accurately replicating the field experiences of another scholar. Philosopher Susan Brison $(2002,102)$ writes that narrative "is a social interaction-actual or imagined or anticipated or remembered-in which what gets told is shaped by the (perceived) interests of the listeners, by what the listeners want to know and also by what they cannot or will not hear." Differences in ethnic and national background, culture, age, gender, and personality all matter, even in the most straightforward interviews. The traits of the researcher can significantly affect the type and amount of information that is gathered, particularly in oppressive, insecure, and post-conflict environments. Part of the intrinsic value of field interviews is the unique interactive experience between researcher and respondents.

The scientific ideals of random selection and methodologically generalizable sampling schemes often are not possible, or affordable, in a genocidal context. In these situations, accomplished scholars are

\section{The DA-RT versions of protection, replicability, and transparency undermine the integrity of field research and can threaten the security of researchers and respondents.}

The ethics of protection are quite different in an authoritarian post-genocide state than in a nonauthoritarian, nonviolent research environment. Researchers must balance the desire for valuable information, risks to personal security, and protection needs of informants. In general, the non-negotiable practices of anonymity and confidentiality are vital to protecting both research subjects and researchers in politically fragile or oppressive environments. In some flexible and adapt their research design to the realities of their surroundings. Many researchers in authoritarian or insecure environments find that sources of information evolve informally on the ground, requiring face-to-face meetings and the building of trust. Authoritarian governments often hinder the flow of information in and out of their country so that it is difficult to build a network of contacts in advance. ${ }^{4}$ In Cambodia, I learned the most from people 
who I did not know existed until I arrived. Think of the woman selling sugarcane from a cart near the temple; she was not someone that my Cambodian research assistant could have contacted in advance. Because these factors confound the demands of social science research ideals, scholars typically do not highlight the role of randomness, coincidence, and dumb luck in completing their projects. Yet, those factors immensely enriched my research findings in Cambodia. Paradoxically, one aspect of transparency is implicitly discouraged in the discipline-that is, an open portrayal of our own experiences as researchers. scholar. I can identify with the researcher working in Guatemala who found herself surrounded by armed men: "I told myself that it would be nonsensical to worry about myself when everyone around me was in greater danger" (Ross 2009, 186).

Many scholars have noted the physical and psychological strains from working in insecure and oppressive environments. Loyle and Simoni $(2017,142)$ use the term "research-related trauma," which "refers to the psychological harm that emerges from exposure to death or violence while engaging in research." Advising researchers to avoid harm, Mertus (2009, 166) warns,

\section{Paradoxically, one aspect of transparency is implicitly discouraged in the discipline - that is, an open portrayal of our own experiences as researchers.}

Thomson, Ansoms, and Murison $(2013,5)$ observe that "in writing up research, senior academics and dissertation committee members advise younger researchers to adhere to standard academic publishing protocols. This usually means adopting methodologies that demonstrate that what we did was planned every step of the way...." That standard advice does not reflect the reality of field research, and it can impede progress by creating unrealistic and inappropriate standards for younger scholars. In reality, researchers struggle to reconcile the differences between our home settings and the "field," including cultural differences in interpersonal relations, government surveillance and bureaucracy, postconflict and traumatic environments, economic inequality, and threats to personal security. The resulting research product generally makes no mention of the "unscientific" aspects of field research. Thomson, Ansoms, and Murison (2013, 11) concurred "that personal dilemmas do affect the research process... [and are] often concealed in the final work to support one's credibility as a researcher." Valuing honest transparency over disciplinary conformity would benefit our understanding of research in challenging circumstances and, in particular, help less-experienced scholars cope with the physical and emotional toll of working in such a context.

\section{EMPATHY, TRAUMA, AND TRUTH}

That emotional toll blindsides me after I return from Cambodia. Back in the United States, I sit in my peaceful office, my desk cleared to accommodate my research notes and messy drafts, with a cup of tea, plants on the windowsill, a new calendar with soothing Japanese nature prints. Yet, every time I try to reflect on the shattered survivors, a searing headache blocks my progress. I feel out of place. My office has too many hard edges and unforgiving plains: white, white walls and carpet the color of ashes, ghastly fluorescent lighting. My anxiety rises as I confront my inability to return to my field-research experiences. To escape, I agree to participate in a different project, temporarily staving off further encounters with genocide.

In the meantime, what do I do with all those unwanted emotional byproducts of my research-the helpless sorrow, the fear and anger churning in my gut? I ignore them; I bottle them up. (Spoiler alert: This is a bad idea.) My academic training tells me that my emotions are irrelevant and could undermine the scholarly rigor of my findings. My reactions in the field are affected by both empathy with trauma victims and acknowledgment of my privileged position as a Western
"Additional critical concerns result from the severe stress of working with traumatized populations, living under the watch of an authoritarian state, traveling in highly militarized zones, and exposing oneself to continual danger." Apparently, I am not some weird anomaly. In fact, "often researchers can feel exhausted after an intense experience and even want to block out everything related to the trip, including their research topic" (Martin-Ortega and Herman 2009, 240). Why didn't someone tell me this beforehand? After Begley $(2013,82)$ returned from Rwanda, she wrote: "For months, I could not look at my field notes nor did I want to discuss what happened. I wanted nothing more than to forget everything. I suffered from panic attacks, nightmares, migraines and I was diagnosed with Post-Traumatic Stress Disorder." I realize that the distress imposed by my experiences with traumatized genocide survivors has triggered memories of my own past traumas. Experts in neurobiology teach us that trauma "can occur if, during a stressful experience, we also perceive ourselves to be powerless, helpless, or lacking control" and that "trauma is especially likely to result if aspects of the current threat or challenge contain cues or triggers related to traumatic events from earlier in our lives" (Stanley 2019, 14; italics in original). Immersed in the aftermath of genocide, I sense that nothing can ever right those wrongs-certainly nothing I can do.

Part of my stress stems from my reluctance to share my experiences. I feel guilty about inflicting descriptions of skull piles and torture chambers on unsuspecting audiences-including friends and family who think my research is an adventure. It is as though I know a dark secret about the calculated cruelty and pain that one person can inflict on another, and I want to spare my listeners this knowledge. For my public presentations, I omit the most chilling photographs, the gruesome descriptions that I cannot get out of my head. I cannot bear to share this knowledge, yet I also cannot bear it alone.

\section{THE WAY FORWARD...}

My story offers a glimpse into one person's experience, into the unpredictable reality of working in politically and personally challenging environments. In life as in research, sometimes we find that personal narrative reveals valuable truths because of its uniqueness, not in spite of it. I find a certain beauty in connecting with someone generous enough to share their personal story. That connection is a fragile gift, worthy of respect and protection. The mass of data gleaned from a personal interview far exceeds a 
transcript of the conversation. Which emotions accompany the words? How do other people react to the storyteller? Which sights and sounds invade our senses? How do cultural mannerisms convey relationships and power structures? The entirety of the experience provides the data necessary for answering these questions.

Methodological trends in our discipline devalue the humancentric research approach that can help discover the perceptions and motivations underlying political violence. A human-centric approach requires a broad skill set, including competence in building networks and personal rapport; interpreting nonverbal communication; comprehending and respecting varied cultural contexts; and adapting quickly to unfamiliar-even dangerousenvironments. International field researchers need extensive skills, resources, and time, especially in challenging or violent areas. Access to information may depend on their willingness to embrace coincidence, serendipity, and luck. Humility is an asset.

The DA-RT principles encourage a skill set less suited for understanding the complexity of genocide. Unlike voter preferences, for example, a researcher is unlikely to find crucial information from analyzing traditional polls or surveys: "Which of the following emotions best describes your state of mind when carrying out ethnic cleansing....?" That reality is what eludes DA-RT. Even if we disregard the ethical obstacles, the requirement to publicly reveal field notes and transcripts would not achieve the transparency envisioned by DA-RT. Because we cannot embody another person's experience or go back in time, researchers cannot adequately replicate their own or anyone else's past interviews and observations. This does not imply that it is impossible to evaluate the quality of field research conducted in challenging circumstances; we have many helpful metrics by which to do so. It means that imposing the DA-RT requirements is inappropriate, misleading, and potentially dangerous, especially for younger and lessexperienced scholars.

Instead of being dictated to by a narrow template of what constitutes ethical research, we can consult experienced researchers about the ethical dilemmas they face and the tools they need to best ensure physical and psychological protection. This will necessitate a more flexible and better-informed IRB process that relies on area experts to determine ethical and safe research procedures. Graduate students deserve better preparation for the reality of unplanned events and exposure to trauma when studying political violence. Loyle and Simoni $(2017,142)$ concurred that dissertation advisers have "a responsibility which extends to monitoring the basic mental health and well-being of their students." Making these changes opens the discipline to a wider range of intellectual inquiry and welcomes more diverse narratives into the field.

For those readers undertaking new research, as you proceed, gather more stories. Look for mentors. Line up a therapist (just kidding). Rehearse imaginary scenarios and think about how you would protect your subjects and yourself using the norms of ethical field research, which far outpace standardized protocols (e.g., a signed consent form). By engaging in this messy, imperfect enterprise, you ensure one thing: your research will become part of the story of your life. "

\section{NOTES}

1. Observations by the author at the Choeung Ek Genocidal Center, Cambodia (November 6, 2012).

2. Personal observations and interviews with the author at Wat Champuh Ka-Ek in Kandal province (November 10, 2012).

3. Thomson (2011) describes that experience in "Reeducation for Reconciliation: Participant Observation on Ingando." The other two researchers spoke on condition of maintaining confidentiality.

4. Fujii's (2009) work provides an example of meticulously planned and executed field research in which she spent months in Rwanda setting up her research plan.

\section{REFEREN C ES}

Begley, Larissa. 2013. "The RPF Control Everything! Fear and Rumour under Rwanda's Genocide Ideology Legislation." In Emotional and Ethical Challenges for Field Research in Africa: The Story Behind the Findings, ed. Susan Thomson, An Ansoms, and Jude Murison, 70-83. New York: Palgrave Macmillan.

Brison, Susan J. 2002. Aftermath: Violence and the Remaking of a Self. Princeton, NJ Princeton University Press.

DA-RT. 2012. 2012 DA-RT Ethics Guide Changes. Available at www.dartstatement. org/2012-apsa-ethics-guide-changes.

Elman, Colin, and Arthur Lupia. 2016. "DA-RT: Aspirations and Anxieties." Comparative Politics Newsletter 26 (1): 44-52.

Fujii, Lee Ann. 2009. Killing Neighbors: Webs of Violence in Rwanda. Ithaca, NY: Cornell University Press.

Fujii, Lee Ann. 2016. “The Dark Side of DA-RT.” Comparative Politics Newsletter 26 (1): 25-27.

Lischer, Sarah Kenyon. 2019. "Narrating Atrocity: Genocide Memorials, Dark Tourism, and the Politics of Memory." Review of International Studies 45 (5): 8o5-27.

Loyle, Cyanne E., and Alicia Simoni. 2017. "Researching under Fire: Political Science and Researcher Trauma." PS: Political Science \& Politics 5o (1): 141-45

Martin-Ortega, Olga, and Johanna Herman. 2009. "There and Back: Surviving Research in Difficult Situations." In Surviving Field Research: Working in Violent and Difficult Situations, ed. Chandra Lekha Sriram, John C. King, Julie A. Mertus, Olga Martin-Ortega, and Johanna Herman, 227-41. New York: Routledge.

Mertus, Julie A. 2009. "Maintenance of Personal Security: Ethical and Operational Issues." In Surviving Field Research: Working in Violent and Difficult Situations, ed. Chandra Lekha Sriram, John C. King, Julie A. Mertus, Olga Martin-Ortega, and Johanna Herman, 165-76. New York: Routledge.

Ross, Amy. 2009. "Impact on Research of Security-Seeking Behavior." In Surviving Field Research: Working in Violent and Difficult Situations, ed. Chandra Lekha Sriram, John C. King, Julie A. Mertus, Olga Martin-Ortega, and Johanna Herman, 177-88. New York: Routledge.

Stanley, Elizabeth A. 2019. Widen the Window: Training Your Brain and Body to Thrive during Stress and Recover from Trauma. New York: Penguin Random House.

Thomson, Susan. 2011. "Reeducation for Reconciliation: Participant Observation on Ingando." In Remaking Rwanda: State Building and Human Rights after Mass Violence, ed. Scott Strauss and Lars Waldorf, 331-39. Madison: University of Wisconsin Press.

Thomson, Susan, An Ansoms, and Jude Murison. 2013. "Introduction: Why Stories Behind the Findings." In Emotional and Ethical Challenges for Field Research in Africa: The Story Behind the Findings, ed. Susan Thomson, An Ansoms, and Jude Murison, 1-11. New York: Palgrave Macmillan.

Tripp, Aili Mari. 2018. "Transparency and Integrity in Conducting Field Research on Politics in Challenging Contexts." Perspectives on Politics 16 (3): 728-38. 